\title{
Tissue Engineering - eine Standortbestimmung
}

\section{Tissue Engineering - Update}

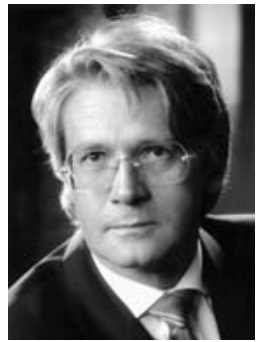

N. M. Meenen

Bibliografie

DOI $10.1055 / \mathrm{s}-2008-1038354$ Z Orthop Unfall 2008; 146: 19 20 (c) Georg Thieme Verlag KG Stuttgart $\cdot$ New York ISSN 1864-6697

Korrespondenzadresse Prof. Dr. Norbert M. Meenen Zentrum für Operative Medizin Unfall-, Hand- und Wiederherstellungschirurgie

Universitätsklinkum HamburgEppendorf

Martinistraße 52

20246 Hamburg

meenen@uke.uni-hamburg.de
Tissue Engineering ist ein interdisziplinäres Konzept. Neben Chirurgen und Biologen waren von Anfang an auch Ingenieure in diese Projekte eingebunden, weil abgesehen von biologischen Fragen technische Aspekte eine Rolle spielen. Beim Tissue Engineering (TE) werden wenige körpereigene Zellen in vitro durch Vermehrung der Zellzahl und anschließender Kultivierung dazu gebracht, durch Verletzungen oder Krankheit zerstörtes Gewebe neu zu bilden. Jahrelang wurde an resorbierbaren und biokompatiblen Matrixmaterialien gearbeitet. Hier waren Keramiker, Biochemiker und vor allem Textilingenieure führend. Bioreaktoren vereinfachen das sterile Handling der Zellen und ermöglichen ein mechanisches Training. Bioverfahrenstechniker konnten hier ihr Wissen aus industrieller (upscaled) Nutzung mit solchen Reaktoren einbringen.

Einer der Pioniere in der Gewebezüchtung, Jay Vacanti, versuchte früh zusammen mit Bob Langer vom Massachusetts Institute of Technology (MIT), den zerstörten Teil eines Fingers durch ein mehrgewebiges TE-Produkt aus dem Labor zu ersetzen. Für internationales Aufsehen sorgte er 1985 mit seiner „Ohrmaus“. Ein mit Knorpelzellen besiedelter Polymerkörper wurde in der Form eines menschlichen Ohres subkutan auf einem Mausrücken implantiert und war auf Titelseiten rund um die Welt zu sehen.

Der Tissue-Engineering-Ansatz, Gelenkknorpeldefekte durch TE-Gewebe zu ersetzen, ist heute der wohl erfolgversprechendste. Der Grund hierfür ist die Sonderstellung des Gewebes: Knorpel besteht aus einem einzigen differenzierten Zelltyp und der von ihm produzierten Matrix. Durch Gewebekultur dieses einen Zelltyps kann funktionsfähiger hyalinähnlicher Knorpel im Labor hergestellt und zur Transplantation verwendet werden. Eine Fixierung des Knorpelgewebes im subchondralen Knochen kann z.B. mithilfe von Kalziumphosphat-Strukturaten erreicht werden, auf die der Knorpel während der Gewebedifferenzierung aufwächst.

Einen anderen Weg gingen 1994 die Schweden Mats Brittberg und Lars Peterson. Sie stellten eine größere Serie von Patienten vor, bei denen sie chondrale Defekte mit einer hochkonzentrierten Aufschwemmung von proliferierten autologen Zellen behandelt hatten, die zur Fixierung im Defekt unter einer Periostschicht verbracht wurden. Im Gegensatz zu der kompletten Invitro-Gewebezüchtung im Rahmen des TE kann man sich bei dem als autologe Chondrozytentransplantation (ACT) bezeichneten Verfahren vor der Implantation noch nicht von der bioche- mischen und biomechanischen Qualität der Produkte überzeugen: Das definitive belastungsfähige Produkt entwickelt sich erst im Verlauf von Wochen und Monaten vor Ort im Defekt.

Die Knorpelzüchtung im Tissue-EngineeringVerfahren und das konzeptionell verwandte Verfahren der autologen Chondrozytentransplantation (ACT) müssen sich der Konkurrenz erfolgreicher existierender Therapieverfahren stellen. In dieser Ausgabe von Orthopädie und Unfallchirurgie veröffentlichen wir zwei Arbeiten zur Behandlung von Knorpeldefekten durch zellbasierte Transplantate $[1,2]$. Es wird einmal ein Vergleich zwischen der ACT und der Mikrofrakturierung und der Mosaikplastik angestellt, wobei sich sowohl in der klinischen Beurteilung wie in der Kosten-Nutzen-Analyse positive Aspekte für die ACT ergeben.

Aufgrund von Handlingproblemen, besonders mit dem Periost, und wegen zu unterschiedlicher Knorpelqualität wurde das Brittberg-Konzept inzwischen durch matrixassoziierte Verfahren der Implantation der proliferierten Zellen (MACI) ersetzt. Hierbei werden die Zellen in Matrixträgern gezüchtet und implantiert. Als Träger finden kollagene Fasern und Gele, synthetische resorbierbare Polymere oder Hyaluronsäurestrukturate Verwendung.

Diesen Ansatz wählt auch die zweite in diesem Heft vorgestellte Arbeit. Sie beleuchtet ein neues klinisches Implantatkonzept an 13 Patienten, bei denen osteochondrale Defekte zunächst mit autologer knöcherner Struktur gefüllt und dann mit einer matrixassoziierten Knorpelzelltransplantation (MACI) gedeckt werden. Die Ergebnisse stellen sich vielversprechend dar und dokumentieren die Verwendbarkeit auch für große knöcherne Defekte einer Osteochondrosis dissecans.

Neben den zellbasierten Transplantationen von Knorpelgewebe wird ein Tissue Engineering von Knochen und von Sehnengewebe experimentell bearbeitet und begrenzt klinisch eingesetzt: Im ZMK-Bereich werden poröse KalziumphosphatTräger mit osteoblastären Zellen beschichtet und implantiert. Bei Knochendefekten am übrigen Skelett werden synthetische Knochenersatzmaterialien mit Knochenmarkszellen beimpft. Es entstehen dadurch jedoch keine vitalen keramoossären Implantate, es wird nur eine bessere knöcherne Integration der Implantate erreicht. Aktuelle Studien arbeiten an Konzepten der Gefäßinduktion, um eine vaskuläre Erschließung der Implantate zu erreichen, weil nur so eine Integration in den vitalen Knochen und ein Remodeling 
möglich werden. Für die experimentellen TE-Entwicklungen von Sehnengewebe wird vornehmlich auf die Verwendung von strukturierten Matrixfasern und Einsatz von spezifischen Wachstumsfaktoren gesetzt.

Bei der Diskussion über die zellulär uniformen TE-Produkte von Gelenkknorpel ist nicht zu vergessen, dass sich die Forschung seit Jahren sehr aktiv mit dem Tissue Engineering von lebenswichtigen Organen wie Leber, Nieren, endokrinem Pankreas und Herzmuskelgewebe beschäftigt. Ein kritischer Punkt ist hier die Integration von Blutgefäßen, die für Struktur und Funktion solcher Organe unentbehrlich ist. Für diesen Aspekt sind die Fortschritte teilweise noch marginal, sodass z. B. bei klinisch erforderlichem Leber- und endokrinem Pankreasersatz vielfach proliferierte Zellaggregate zum Einsatz kommen. Konzeptionell einfacher sind experimentelle TE-Projekte für Gefäße und Herzklappen, bei denen resorbierbare tubusförmige Matrixstrukturate durch Endothelzellen biologisiert werden.

\section{Wie kann sich Tissue Engineering von Gelenk- knorpel weiter entwickeln? \\ $\nabla$}

Trägermatrices spielten für den zellbasierten Knorpelersatz in den letzten Jahren eine bedeutende Rolle. Nur wenige Arbeitsgruppen haben den mesenchymalen Zellen selbst die Aufgabe überlassen, primär den gesamten auch strukturellen Aufbau der Gewebe zu übernehmen. Die synthetische oder biogene Matrix (z.B. Kollagen) muss allerdings wieder aus dem Gewebeverbund abgebaut und resorbiert werden. Dieser in einer reinen Knorpelzellumgebung kritische Vorgang mag die möglichen Vorteile seiner Verwendung schließlich neutralisieren. Auch sind die Invitro-Kultivierungen mit einem hohen technischen und ökonomischen Aufwand verbunden, Bioreaktoren und Wachstumsfaktoren unverzichtbar. Kritische molekularbiologische Untersuchungen zum heute erreichbaren Differenzierungstatus der proliferierten Zellen veranlassen daher immer wieder, nach Alternativen der MACI in der derzeitig durchgeführten Form zu suchen. Eine zuverlässige Redifferenzierung von proliferierten Knorpelzellen oder adulten Stammzellen ist nur begrenzt zu erlangen, die biochemische und biomechanische Qualität des natürlichen
Knorpels wird bei den Produkten kaum erreicht. Die Anwendungsergebnisse rechtfertigen oft nicht den Produktionsaufwand.

Möglich ist also, dass es nicht zu einer Erweiterung des klinischen Einsatzes von Gelenkflächenersatz nach solchen TissueEngineering-Verfahren kommt. Daher werden wohl zukünftig Konzepte der In-situ-Regeneration entwickelt, bei denen die lokalen körpereigenen Zellen aus dem erschlossenen Subchondralraum das benötigte regenerative und reaktive Potenzial aufweisen. Dafür ist von zentraler Bedeutung, dass in situ eine nahezu unbegrenzte Zahl an regenerations- und differenzierungsfähigen Stammzellen und alle notwendigen Wachtumsfaktoren zur Verfügung stehen. Es müssen allerdings wesentliche natürliche Regenerationshindernisse erkannt und durch Folien oder Matrices aus dem Regenerations-Compartment ferngehalten werden. Der Körper stellt dann die idealen Kulturbedingungen zur Verfügung, die ein Bioreaktor nur simulieren kann. Die funktionelle Beanspruchung durch frühzeitige Bewegungsübung wird die Differenzierung und Matrixsynthese stimulieren. Man könnte dieses Verfahren dann wohl als „microfracture de luxe" bezeichnen.

Bis dahin wird die Gewebekultur in vitro neue Erkenntnisse über die idealen Wachstumspromotoren wie auch über die hindernden Faktoren der bekanntermaßen in vivo kaum ausgeprägten Regenerationstendenz des adulten Gelenkknorpels geliefert haben. Dann kann das Verfahren der In-situ-Regeneration im Vergleich zum Tissue Engineering in vitro sicherer, möglicherweise besser und billiger und damit erfolgreicher werden.

Die Zeitschrift für Orthopädie und Unfallchirurgie wird die weitere Entwicklung mit großer Aufmerksamkeit verfolgen.

\section{Literatur}

1 Maus U, Schneider U, Gravius S, Müller-Rath R, Mumme T, Miltner O, Bauer D, Niedhart C, Andereya S. Klinische Drei-Jahres-Ergebnisse der matrixgekoppelten ACT zur Behandlung osteochondraler Defekte am Kniegelenk. Z Orthop Unfall 2008; 146: 31 - 37

2 Vavken P, Gruber M, Dorotka R. Tissue Engineering in der Orthopädischen Chirurgie - Klinischer Effekt und Kosten-Nutzen-Analyse der autologen Chondrozytentransplantation im Kurz- und Langzeitmodell. Z Orthop Unfall 2008; 146: 26 - 30 